\title{
Financiamento da Educação: Como garantir o CAQi e o CAQ
}

discussão sobre o custo aluno-qualidade (CAQ) tem sido objeto de estudos e
debates político-pedagógicos complexos, envolvendo dispositivos legais, den-
tre eles, a Constituição Federal, a LDB e o Plano Nacional de Educação, bem como diretrizes e pareceres. Nos debates, ganham evidência e centralidade a relação orgânica entre financiamento e gestão, o papel da União e o dos demais entes federados, o regime de colaboração, a vinculação e subvinculação de recursos para a educação básica (incluindo o Fundeb), a valorização dos profissionais da educação e as políticas expansionistas.

Diante dos embates antevistos sobre o novo PNE e, especialmente, sobre a discussão e materialização do CAQ, entrevistamos três especialistas com larga experiência e engajamentos distintos, porém, todos articulados às lutas pela democratização, melhoria e pelo efetivo financiamento para a educação básica no País: Carlos Augusto Abicalil, Gilmar Soares Ferreira e José Marcelino de Rezende Pinto. A partir de questões formuladas pelos professores Luiz Dourado e Nelson Amaral, com a participação da editora de Retratos da Escola, professora Leda Scheibe, os convidados discutem concepções, limites e possibilidades do financiamento da educação básica no País, especialmente, a materialização do CAQ e do CAQi.

A Lei No 13.005 de 25 de junho de 2014, que aprovou o Plano Nacional de Educação para o período 2014-2024, apresenta nas estratégias da Meta 20 a implementação do Custo Aluno-Qualidade inicial (CAQi) e do Custo Aluno-Qualidade (CAQ). Como explicar em poucas palavras a diferença entre as duas definições? Essas estratégias contemplam satisfatoriamente uma possível implementação do CAQ?

Carlos Augusto Abicalil - O componente distintivo é relacionado à progressividade de sua implementação. Há enormes distâncias entre a capacidade de financiamento de cada ente federativo, entre estados, entre estados e municípios, entre municípios de uma mesma unidade da federação. Há, também, diferenças na capacidade fiscal e no seu aproveitamento, derivado de políticas de incentivos fiscais, da baixa tributação de propriedades e bens, do pouco esforço arrecadatório da maioria dos entes federativos, da baixa capacidade técnica - particularmente de municípios institucionalmente muito frágeis, além dos efeitos notórios da ação concorrencial e da guerra fiscal. As disparidades são agravadas pela ausência de uma referência nacional de aferição e de acompanhamento das capacidades e dos esforços fiscais - por razões que vão desde 
disposições técnicas até as indisposições políticas - ancorados no argumento da autonomia federativa. Essa situação através da dinâmica distributiva do Fundeb - uma subvinculação ancorada em parcelas de impostos transferíveis da União e dos estados implica o desenvolvimento de processos que visem alcançar a totalidade da vinculação obrigatória à educação, incluindo a diversidade das legislações estaduais e municipais, a integralidade de recursos complementares de outras fontes, como aqueles que financiam programas suplementares do FNDE e as cotas estaduais e municipais do salário educação. O desenvolvimento e o aperfeiçoamento das ferramentas de controle e de avaliação (especialmente sobre as capacidades tributárias e os efeitos da guerra fiscal), por um lado, e da "lista de insumos" e de processos capazes de reduzir progressivamente as desigualdades na oferta educacional pública se somam, concomitantemente, ao esforço nacional de alcançar os 10\% do PIB em educação, sem desconsiderar as parcelas necessariamente aplicadas em educação profissional, tecnológica e superior, e nas interfaces entre ensino, pesquisa e extensão.

Gilmar Soares Ferreira - Primeiro, é preciso esclarecer a origem dos debates em torno do custo aluno-qualidade. Na história de luta pelo financiamento público da educação pública e gratuita, os debates sobre o CAQ como critério de reforço do financiamento da educação, ou seja, para a sustentação das condições fundantes de acesso e permanência dos estudantes, valorização salarial e profissional com piso-carreira-formação profissional-e condições de infraestrutura adequadas ao ensino-aprendizagem remontam mais firmemente aos anos finais da década de 80 e toda a década 90, até sua consolidação na aprovação do Plano Nacional de Educação, pela Lei 13.005/2014. Assim, a Constituição Federal de 1988 estabeleceu que deve ser garantido um "padrão de qualidade", ao apresentar os princípios sob os quais o ensino deve ser ministrado no Brasil. Desde a grande conquista na CF/88, a CNTE teve fundamental importância, quando um consenso em torno do Piso Salarial Profissional Nacional do Magistério permitiu a instalação do Fórum Permanente de Valorização do Magistério e Qualidade da Educação Básica. A CNTE, como nos relata o professor João Monlevade em sua tese de doutorado, teve um papel fundamental expresso no compromisso de apresentar para o debate no Fórum "a planilha de viabilização do PSPN". O Governo FHC enterrou qualquer expectativa de avanços significativos, reivindicados por diversas entidades de classe e movimentos sociais, na valorização dos profissionais da educação. Mas as sementes do CAQ e posteriormente do CAQI já estavam plantadas. Com o refluxo momentâneo das políticas neoliberais em educação, com os governos democráticos e populares de Lula-Dilma, o debate de um CAQI e CAQ novamente ganhou centralidade, sobretudo nas conferências educacionais de 2008, 2010 e 2014. Atualmente, todo o debate em torno do CAQi e CAQ refere-se às condições para que, em nível nacional, "se consiga estabelecer uma política que possibilite aos entes federados financiarem adequadamente os CAQ, associados a cada nível/etapa/modalidade da educação básica. Primeiro, como referência inicial e, na 
sequência, buscar a equiparação com os países referencias em investimento em educação pública e gratuita, com retorno na qualidade socialmente almejada. O PNE/2014-2024 explicitou que esse "padrão de qualidade" (arts. 206, VII e212, § 3) se encontra na definição do Custo Aluno-Qualidade inicial (CAQi) e do Custo Aluno-Qualidade (CAQ). O CAQi, que será "referenciado no conjunto de padrões mínimos estabelecidos na legislação educacional e cujo financiamento será calculado com base nos respectivos insumos indispensáveis ao processo de ensino-aprendizagem e será progressivamente reajustado até a implementação plena do Custo Aluno-Qualidade (CAQ)," conforme a Estratégia 20.6 da Meta 20 do PNE 2014-2024.

José Marcelino de Rezende Pinto - O CAQi dialoga diretamente com o Art. 211, § $1^{\circ}$ da CF, que determina: "A União organizará o sistema federal de ensino (...) e exercerá (..) função redistributiva e supletiva, de forma a garantir equalização de oportunidades educacionais e padrão mínimo de qualidade do ensino mediante assistência técnica e financeira aos Estados, ao Distrito Federal e aos Municípios". Ou seja, o CAQi é o recurso a ser assegurado por aluno em qualquer escola do Brasil para garantir as condições de oferta de um ensino de qualidade. Já o CAQ é o passo seguinte; atingido o mínimo, avancemos para padrões de gasto por aluno que se aproximem de uma qualidade social. Uma boa referência para o CAQ são as escolas básicas da rede federal de ensino, que oferecem um excelente padrão de qualidade e custam menos que as escolas privadas frequentadas pela elite. Sobre as últimas, vale a pena dizer que o valor de uma mensalidade dessas instituições corresponde ao gasto anual, por aluno, da rede estadual de SP. O CAQ está previsto desde a EC 14/95 e não foi implantado por omissão vergonhosa do governo FHC. Com o Parecer 8/2010, e com o PNE definindo o prazo para sua implementação para junho de 2016, ele não saiu do papel por omissão também vergonhosa da Sase-MEC, nos governos Lula e Dilma. Basta dizer que esses governos (em especial Lula II e Dilma I) dobraram o gasto educacional federal (Manutenção e Desenvolvimento do Ensino [MDE]) frente ao PIB. Só que o fizeram, no caso da educação básica, através de transferências voluntárias e não através da incorporação do CAQi ao Fundeb, como discutimos em infinitas reuniões com a equipe da Sase-MEC. Com o golpe ficou fácil cortar os recursos, que não estavam vinculados ao CAQi e ao Fundeb. Entendo que as estratégias previstas no PNE são adequadas, até porque o esforço para o CAQi seria ampliar a contribuição federal ao Fundeb de 0,2\% do PIB para 1\% do PIB. Trata-se de um esforço grande, mas realizável, até porque o Governo Federal fica com mais de 16\% do PIB em recursos tributários e, no melhor ano Lula, chegou a 1,2\% do PIB em MDE, em 2012. Em 2018 ele caiu para 0,9\% do PIB, uma perda de $0,3 \%$ do PIB. Considerando que o complemento da União gira em torno de $0,2 \%$ do PIB, se incorporados ao Fundeb, esses recursos extorquidos à educação pelos últimos governos propiciariam um complemento de $25 \%$, ante os $10 \%$ ou $15 \%$ assumidos pelo MEC na proposta do novo Fundeb. 


\section{Considerando a importância de se definir e materializar o CAQ na educação básica brasileira, esta temática não deveria ter sido explicitada como uma Meta do PNE?}

Gilmar Soares Ferreira - Se consideramos a necessidade da maioria da população que matricula seus filhos/as na escola pública e depende exclusivamente da educação gratuita, responderemos que sim. Mas se nosso olhar vislumbrar a disputa de dois projetos educacionais, sendo que as elites atuam para impedir ou atrasar o acesso da maioria da população ao conhecimento, ou seja, à creche, a pré-escola, ao ensino fundamental e médio público, gratuito e de qualidade socialmente referenciada, nossa resposta será "não". É nesse sentido que, pela segunda vez, um Plano Nacional de Educação está sendo desconstituído/destruído na sua "espinha dorsal", que é o financiamento das suas metas com recursos públicos em instituições públicas. Está comprovado que as elites nacionais, em estreita relação com o capitalismo rentista mundial, não têm interesse que os orçamentos públicos estejam a serviço da maioria da população. Para as elites locais e internacionais, a educação pública não passa de mera mercadoria. Por isso, não pode ser totalmente gratuita. Então, os elementos de definição do CAQ e CAQI impõem uma delimitação fronteiriça entre "direito" e "mercado". A condição de "Direito" conquistada na $\mathrm{CF} / 88$ é entrave às pretensões empresariais ou de ONGs e representantes de grandes empresários, que buscam nas políticas de criação das bases curriculares pré-definidas - BNCC da EI e EF e no caso do ensino médio, a flexibilização curricular - as condições para vender seus pacotes de conteúdos e treinamentos de pessoal, bem como hardwares e softwares da educação transformada em mercadoria.

José Marcelino de Rezende Pinto - Acho que isso é o de menos. O conceito do CAQ já está expresso no Art. 211 da CF. As propostas de Fundeb permanente (PEC 15/2015, versão de Setembro/2019, Substitutivo da relatora deputada Dorinha Seabra Rezende e PEC 65/2019 do Senado, que tem como relator o senador Flávio Arns) avançam bastante em colocar, com todas as letras, o CAQ na CF, onde ele aparece desde a EC 14/96. No caso do Substitutivo da Câmara, ele encontra-se na inclusão do § $7^{\circ}$ ao Art. 211 da CF.

Carlos Augusto Abicalil - Frente às tensões antes e depois da aprovação do PNE e da estratégia traçada na Câmara dos Deputados para atingir o mais amplo consenso na Comissão e no Plenário (obtendo, por fim, voto unânime), a fórmula resultante no texto aprovado possui consistência nitidamente superior à previsão apenas nominada na regulamentação do Fundeb e na EC 53/2006. Iniciemos por conferir o artigo 5º. no corpo da Lei do PNE, e a especial atenção aos parágrafos $3^{\circ}$, $4^{\circ}$ e e $5^{\circ}$. A leitura da Meta 20 e de suas estratégias se faz sob os marcos gerais sobre como considerar o investimento público em educação. O detalhamento das estratégias busca resolver boa parte das debilidades de enfrentamento do tema, já considerando aspectos abordados no Parecer CEB/ CNE 8/2010, nas sucessivas alegações em torno de sua não homologação pelo MEC, ainda antes da apresentação do PL e da aprovação do PNE. Há um conjunto orientador
“Está comprovado que as elites nacionais, em estreita relação com o capitalismo rentista mundial, não têm interesse que os orçamentos públicos estejam a serviço da maioria da população."

(Gilmar Soares Ferreira) 
e compreensivo bastante consistente frente às variadas frentes de resistência, particularmente das áreas de economia e finanças públicas das três esferas federativas. A aprovação unânime do texto PNE resulta num potente argumento para as regulações em tramitação no Congresso Nacional: o chamado Fundeb Permanente (ou Novo Fundeb) e a Lei Complementar sobre a cooperação federativa, a colaboração entre os sistemas de ensino e a instituição do Sistema Nacional de Educação. Por outro lado, superou, paralelamente, o questionamento sobre o limite de competência do Conselho Nacional de Educação deliberar sobre a regulamentação pendente.

\section{A Emenda Constitucional $N^{0} 95$ congelou os recursos financeiros associados às despe- sas primárias (salários, água, luz, limpeza, vigilância, telefone, material de consumo etc.) do Poder Executivo até 2036. Será possível cumprir as estratégias da Meta 20 rela- tivas ao CAQ? Seria possível comprimir os orçamentos dos demais ministérios para priorizar os recursos do MEC no contexto do Poder Executivo?}

Gilmar Soares Ferreira - Excetuando as metas que, por força de pressão e lobby do mercantilismo na educação, serão facilmente implementadas para favorecer a terceirização, privatização e subtração do direito à educação pública e gratuita, todas as metas que necessitam do provisionamento dos recursos públicos, providos via orçamento, estão seriamente comprometidas. A única via de barrar o atual projeto em curso é anular, desde o período do golpe que destituiu a presidenta legitimamente eleita do poder, os atos emitidos por decretos e/ou que por medidas provisórias e relações fisiológicas do Executivo com o Congresso impuseram derrotas à maioria da população em termos de garantias constitucionais para a assunção do direito à educação pública, gratuita e de qualidade. No atual projeto, não há e não haverá espaço nem mesmo para realocação ou compressão de recursos de outros ministérios, uma vez que a "ordem" é privatizar ou vender tudo o que for possível. Estamos diante de uma tragédia do ponto de vista da educação, pois o próprio País (leia-se: elites e grande parte das autoridades e instituições) consente no desmonte do Estado de Direito Constitucional, parcamente conquistado em 1988. O resultado da destruição do Estado de Direito será o recrudescimento da crise de humanidade à maioria, imposta pelas elites nos últimos 500 anos. Quando o povo, na sua maioria, não se vê assistido nas suas necessidades básicas, o resultado poderá ser a barbárie das relações individualistas ou de facções que, de forma paralela ao Estado, atuam para tornar a vida ainda mais desafiadora e crítica. O financiamento da educação pública e gratuita, garantindo as condições de acesso e permanência com critérios de resgate à dignidade e à condição humana é o grande desafio do presente. $\mathrm{O}$ mais cruel deste momento é que se não escolhermos por via de projeto social de inclusão, o faremos pela dor da destruição das condições humanas e de natureza biológica e animal. 
José Marcelino de Rezende Pinto - Antes de mais nada, a complementação da União ao Fundeb escapa ao congelamento previsto nessa monstruosidade chamada EC 95/2016. De qualquer forma, a EC 95 deve ser revogada, pois até os interesses dominantes do setor privado assim o desejam, pois ela inviabiliza a administração federal e os investimentos públicos de que o capital privado tanto gosta. Essa emenda foi uma ação nefasta de funcionários de grandes bancos nacionais e internacionais (Levy, Meireles etc.), que, com apoio da mídia, desde Dilma II, tomaram de assalto o Estado brasileiro sem ter que pedir um voto popular para seus planos macabros. O grande erro de Lula foi sua ingenuidade, ao pensar que a elite brasileira seria compreensiva com ele, por tudo que fez aos ricos e pobres. Vargas, por se originar da elite, conhecia bem o tipo de gente que manda no País. O risco que vivemos seria uma alteração na EC 95, mas só para facilitar o interesse privado, mantendo o congelamento dos gastos sociais. Seria o pior dos mundos.

Carlos Augusto Abicalil - A implementação da Meta 20 e de todas as metas que vislumbrem expansão e valorização da oferta pública fica absolutamente inviabilizada com a EC 95. Ainda que haja progressão positiva nas receitas públicas, a EC 95 impede o crescimento real dos gastos públicos. Seu fundamento é a reserva para o pagamento da dívida, eventual investimento em PPP e maior redução da carga tributária para setores empresariais. Valem dois registros adicionais agravantes aqui: a) a meta da atual equipe econômica de redução de $33 \%$ para $22 \%$ na carga tributária total frente ao PIB e a desvinculação total dos orçamentos públicos (incluindo impostos, não apenas taxas e contribuições); b) os efeitos previstos da PEC 45/2019 - Reforma Tributária, tramitando na Câmara dos Deputados - que funde o somatório dos gastos efetivos em educação e saúde para efeito das correções inflacionárias posteriores à vigência, amplia a injusta tributação sobre consumo com dois efeitos práticos perversos e previsíveis - exacerba a regressividade da carga tributária (quem tem menos paga mais) e reduz progressivamente a participação do financiamento da educação e da saúde em percentuais do PIB.

\section{Como avaliar o fato de já estarmos no sexto ano de vigência do PNE e nenhuma ação para a implementação do CAQi ter sido efetivamente tomada?}

José Marcelino de Rezende Pinto - Desses seis anos, dois podem ser colocados na conta de Dilma Roussef e de Binho Marques. Este último produziu um relatório de que se valeu Maria Helena de Castro para tentar enterrar o CAQi no CNE. Não conseguirão. Se o governo Dilma tivesse aprovado um CAQi no Fundeb, mesmo que com um aumento escalonado na complementação da União (nas emendas em discussão na Câmara e Senado o prazo é de dez anos, começando com 15\%, na Câmara e em 20\%, no Senado), a situação dos golpistas seria muito mais difícil. Teriam contra si os 5.700 prefeitos e 27 governadores. Depois do golpe e com o anticristo, o que aconteceu era o
“.... a EC 95 deve ser revogada, pois até os interesses dominantes do setor privado assim o desejam, pois ela inviabiliza a administração federal e os investimentos públicos (...).” (José Marcelino Rezende Pinto ) 
"A realidade

é pior: houve

a modificação

substantiva

da posição do

Conselho Nacional

de Educação

sobre o tema, em

texto aprovado

ainda antes do

próprio PNE..."

(Carlos Augusto

Abicalil) esperado. Mas eles passarão. Corrigindo, passarão a depender de nossa capacidade de convencer os segmentos populares que nele votaram da arapuca em que se meteram.

Carlos Augusto Abicalil - A realidade é pior: houve a modificação substantiva da posição do Conselho Nacional de Educação sobre o tema, em texto aprovado ainda antes do próprio PNE, um importante subsídio para o debate e a normatização nacional; o PNE é mencionado residualmente na Mensagem ao Congresso, apresentada pelo presidente em 01/02/2019; seus ministros de educação reiteram que o Brasil já "gasta" o suficiente em educação, opõem o financiamento da educação básica à educação superior; sustentam que qualquer recurso transferível deve vincular-se a premiar resultados; fraturam a oferta pública com a defesa da 'liberdade de escolha das famílias", com vouchers à educação privada ou domiciliar.

Gilmar Soares Ferreira - Para entender o processo de secundarização do PNE em vigência, temos que compreender o contexto de disputa de projeto de educação em relação à disputa de modelo de sociedade no País. Na luta por uma sociedade baseada no direito e na inclusão econômica, cultural e social, a CF/88 é um marco temporal central. Desde a promulgação, a Carta Magna possibilitou às grandes maiorias (minorias quando a questão é disputa de espaços de poder e dinheiro) sonhar com uma sociedade mais justa e igualitária. Foi em contraposição a este projeto, que o atual presidente, legítimo representante dos setores entreguistas da Nação ao capitalismo internacional, capitaneado pelos EUA, inclusive do setor militar, referiu em seu discurso de posse "acabar com o socialismo no Brasil". Mesmo com a CF/88, esse projeto social teve dificuldades de ser levado adiante, face as forças conservadoras do poder e as estruturas concentradoras de renda e negadoras de educação, segurança e saúde públicas e gratuitas para a maioria da população, bem como cultura, lazer, moradias, dentre as necessidades básicas para sobreviver. Essa elite de direita, conservadora, desvinculada de um projeto nacional não tem interesse em desenvolver o País para seu próprio povo. Essa mesma elite se viu ameaçada, num curto espaço de tempo, por governos democráticos e populares e suas políticas mínimas de investimento e direcionamento que mudaram a vida de dezenas de milhões de brasileiros. Essa elite percebeu que instrumentos como Fundeb (EC 53), ampliação da escolaridade obrigatória (EC 59), PNE (Lei 13.005/14), dentre inúmeros projetos e programas que beneficiavam a população de baixa renda, o curso do desenvolvimento local e nacional conduziriam a um processo que exigiria duras reformas a implodir a concentração e a exploração da renda no Brasil, reduzindo a possibilidade do lucro fácil pela exploração semiescrava da população. Por isso, essa elite não somente inviabiliza e inviabilizará o PNE (2014-2023), como também impôs a reforma do ensino médio, a reforma trabalhista, a reforma previdenciária em curso e a tramitação da reforma tributária, que também não favorecerá à classe trabalhadora. Todos esses movimentos visam aprofundar as amarras do Estado centralizador, fiscalista e burocrático, para manter a atual ordem econômica mundial e seus interesses sobre o Brasil. Há que se lembrar que o 
processo de golpe, que culminou no impedimento da presidente Dilma, teve início bem antes da sua reeleição, a fim de emperrar as políticas em favor da maioria da população. Em termos de educação, a pesquisa sobre mercantilização da educação realizada pela UnB/CNTE/IE já demonstrava o alto poder de lobby de ongs e representantes de empresários interessados em processos privatizantes da educação no Brasil.

\section{O parecer CNE/CEB-8/2010, aprovado desde maio de 2010, estabeleceu parâmetros para a implementação do CAQi. Entretanto, a Resolução aprovada nunca foi homologada pelo Ministério da Educação. O que dizer sobre esta atitude do MEC, desde 2010?}

Carlos Augusto Abicalil - A pergunta acaba por confirmar o que comentei antes. Estive no MEC durante 13 meses, entre janeiro de 2011 e abril de 2012, na criação e implementação da Secretaria de Articulação com os Sistemas de Ensino (Sase). Internamente, a tramitação de pareceres do SNE se situava a cargo do Gabinete Ministerial, ouvida a Secretaria de Educação Básica e as assessorias jurídicas, uma vez que se constitui em prerrogativa de ministro de Estado. Ao conformar o Planejamento Estratégico da Sase, incluímos uma ação articulada, que resultou, depois de muito debate interno e com o apoio das secretarias Executiva e Executiva Adjunta de então, na proposta de um Fórum de Avaliação e Financiamento da Educação Básica, dois anos depois, envolvendo vários órgãos governamentais, representações de estados e municípios e sociedade civil, convergindo na consideração da totalidade dos recursos vinculados nas três esferas, na revisão dos critérios de ação redistributiva e suplementar do FNDE e na consideração das cotas estaduais e municipais do salário educação. Outra tensão simultânea também oriunda da $\mathrm{CEB} / \mathrm{CNE}$ dizia respeito à disputa do fundo público por organizações privadas de assessoramento e assistência técnica (ongs, fundações, organizações sociais etc.), que resultaram na formulação dos chamados "Arranjos de Desenvolvimento da Educação", transformados na Resolução 01/2012. Participando das atividades do GT sobre federalismo, territorialidades e cooperação em educação, já sem a titularidade da Sase, reiterei em variadas ocasiões minha preocupação com a interface dos dois temas, as restrições da LRF sobre a ampliação dos gastos com pessoal, a lei de licitações, a tendência de compressão dos gastos com pessoal, particularmente sobre estados e municípios e a desconsideração dos consórcios públicos, estes, sim, regulados em lei como figura não considerada no conjunto de possibilidades. Logramos realizar, também, um seminário nacional conjunto com o Observatório dos Consórcios Públicos, em maio de 2013. Não menos importante, para efeitos do Poder Executivo nas três esferas, é o posicionamento da AGU, articulando suas estratégias de enfrentamento a demandas judiciais em torno do Fundef e do Fundeb, arguindo a um só tempo o pacto federativo, os limites da responsabilidade fiscal, e agregando indicadores de desempenho como referências, inclusive 
"Neste momento, o pensamento da ultra direita conservadora

atua para

anular qualquer

possibilidade de política que exija

mais recursos

federais para efetivar a educação pública."

(Gilmar Soares

Ferreira) para as transferências complementares, como, aliás, já apontavam os órgãos de controle, como o TCU e vários TCE. Argumentos que chegam, agora, aos titulares do próprio MEC.

Gilmar Soares Ferreira - O entendimento de que a educação pública nacional é elemento estratégico de intensa disputa para o domínio econômico é a chave para entender porque todos os segmentos políticos, que vão de centro para a esquerda ou para a direita, defendem a educação inclusiva no discurso, mas a prática fica distante do que foi e é propagado. No caso da visão política de centro para a direita, jamais aceitarão implementar uma educação pública, gratuita, inclusiva, laica e democrática, que atenda com qualidade os anseios da população. Tal educação, se implementada, alteraria o sistema no qual o pensamento político, econômico, moral e conservador, estão ancorados. Nesse momento, assistimos à destruição da educação pública e gratuita como direito pela visão de ultradireita assentada pelo voto direto de parte da população no Governo Federal. Justamente porque veem na liberdade de ensino, no diálogo, na pedagogia da autonomia, da pergunta ou da esperança, que tem Paulo Freire como seu expoente maior na linha da libertação das pessoas nas/das relações de opressão, o risco de implosão do sistema de dominação conservadora. Por isso, nesse momento, projetos com homeschooling e Escola Sem Partido ganham espaço na mídia, nas instituições dominadas pelo conservadorismo. É claro que, nesse contexto, pareceres como o CNE/CEB-8/2010, que apontam para a estruturação das condições de existência de uma escola para atendimento da população como condição universalizante do ensino, jamais poderão prosperar. É curioso que a situação política neste momento difere do desejado por setores da direita, como representantes de ongs, que por sua vez representam empresas, fundações empresariais e instituições "sem fins lucrativos", que lucram com parcerias com o/os governo/ os para se apropriar dos recursos públicos em educação e implementar o viés empresarial no ensino. Diferentemente dos setores de ultradireita, que, ao implementar o viés do neoliberalismo conservador, buscam anular o papel do Estado nos serviços públicos, os setores de direita toleram o Estado, desde que esta abra a possibilidade dos serviços públicos para satisfazer a sede de mercado dos empresários do setor, a exemplo das parcerias público privadas. O parecer CNE/CEB-8/2010, em certo sentido, é resultado dessa visão mercadológica, que disputava por dentro do Governo Federal os recursos públicos da educação. O PNE em vigência deixou brechas nesse sentido para favorecer as parecerias público privadas na educação superior e na básica. As BNCC são exemplo de políticas que interessavam aos setores empresariais. Neste momento, o pensamento da ultradireita conservadora atua para anular qualquer possibilidade de política que exija mais recursos federais para efetivar a educação pública. O resultado dessa visão de educação aprofundará as crises de desenvolvimento de políticas públicas, que já vinham sofrendo com as investidas e os lobbies da iniciativa privada.

José Marcelino de Rezende Pinto - Já falei um pouco sobre esse ponto, mas vale a pena aprofundar. Não foi uma nem duas vezes que recebemos a equipe da Sase-MEC 
na USP, em Ribeirão Preto, para explicar os conceitos do CAQi, fora outras tantas reuniões em Brasília. Havia contra-argumentos para todo gosto. Um, prosaico, questionava por que havia videocassete no CAQi. Ora, porque, quando as planilhas foram feitas, em 2005 (!), esse era um equipamento importante nas escolas, o que mostra a estratégia protelatória do MEC. Outro ponto exaustivamente debatido referia-se à defesa. por parte de Binho Marques, de valores regionalizados para o CAQi. Contra-argumentávamos: desde quando a CNTE defendeu piso salarial regionalizado? E, considerando que mais de $80 \%$ do valor do CAQi corresponde a salários, não há porque se falar em regionalização. Alguém defende salário mínimo regional no Brasil? Ademais, eventuais diferenças de custos ocorrem mais entre capitais e grandes cidades em comparação com pequenos municípios do interior, do que entre diferentes regiões do País. Além do mais, no CAQi da CNDE sempre defendemos os adicionais para municípios e regiões de maior vulnerabilidade, estratégia que, aliás, está prevista no Substitutivo da Câmara do Fundeb. Considerando que o Parecer foi aprovado em maio de 2010 e foi antecedido por inúmeras audiências no CNE e fora dele e foi aprovado por unanimidade, o MEC teve sete anos para fazer algo a favor do CAQi e, ressalto, nunca o fez, só empurrou com a barriga. Por quê? Porque não quis assumir uma política de Estado, ampliando os recursos da União para o Fundeb. O Governo Federal poderia ter duplicado sua complementação ao Fundeb, um passo essencial para o CAQi, apenas com os recursos previstos no orçamento para transferências voluntárias. Optou por tentar deixar sua 'marca', na ilusão de continuidade indefinida no poder. Deu no que deu. Considerando ser esta revista uma publicação da CNTE, para o bem da história, cabe dizer que o CAQi nasceu com a marca da CNTE; a entidade foi fundamental para o cálculo de seu valor. Lembro-me muito bem que foi a CNTE, integrante do diretivo da Campanha Nacional pelo Direito à Educação que forneceu a diretriz de valor do piso salarial de referência do CAQi para um professor com formação em nível médio na modalidade normal e jornada de 40 horas semanais, aí incluída a chamada hora-atividade. Também a CNTE teve papel central na definição do desenho de carreira contemplado nas planilhas do CAQi, bem como em seu parâmetro de remuneração, associado ao nível de formação dos profissionais e não ao tipo de atividade exercido, considerando que todos são trabalhadores da educação. Assim, nas planilhas do CAQi, um professor com formação em nível médio na modalidade normalmente tem a mesma remuneração de uma secretária de escola formada em nível médio na modalidade técnica, para uma mesma jornada. Por falar em história do CAQi, no âmbito da CNDE, além de Daniel Cara, é fundamental citar o esforço pioneiro de Camila Crosso e a ação imprescindível de Denise Carreira, coordenadora da CNDE quando o CAQi foi lançado. Como pioneiros do conceito, cabe citar os nomes de Ediruald de Mello e João Monlevade, além de nossa referência comum: José Carlos de Araújo Melchior. 
O CNE, em reunião do dia 26 de março de 2019, contrariando o estabelecido na Resolução anterior, se declarou sem competência para estabelecer valores financeiros referentes ao CAQi. O que pode ser dito sobre esse retrocesso? Que agentes contribuíram para que ele ocorresse?

Gilmar Soares Ferreira - Neste momento e com este governo, com sua interferência direta nos espaços antes constituídos de forma democrática, principalmente para resguardar os interesses familiares, de amigos, empresários parceiros e adjacentes, nada mais natural. A anulação das entidades e instituições, o isolamento de pessoas, tudo isso caminha no sentido de sequestrar o Estado de sua função constitucional. Como é o poder econômico, baseado no rentismo, quem dita as regras, não aceitariam que o Inep desempenhasse um papel subsidiário de dados e informações, capazes de fomentar nos entes as condições para o financiamento da educação pública, gratuita, laica e de qualidade para todos. Foi o que o Inep fez, dando suporte à publicação do parecer 8/2010. Assim, as estruturas de Estado, diferentemente dos governos democráticos e populares, estão submetidas aos interesses dos agentes do mercado, mais interessados nos preços das ações na Bolsa de Valores, do que, de fato, nas condições de acesso e de ensino-aprendizagem nas escolas. Dessa forma, a educação nacional sofre a ingerência dos grandes grupos nacionais e internacionais, que buscam, através da velha forma de redução de custos, garantir seus lucros e suas empresas. O resultado dessa ingerência empresarial na educação pública já se faz sentir no aumento do número de profissionais contratados precariamente e nas péssimas condições de infraestrutura dos prédios escolares. Pelo País, se alastram as notícias de prédios correndo risco de desabar sobre estudantes e profissionais da educação, escolas de lata, funcionando em contêineres; e já tivemos notícia de professores contratados pelo menor preço, dentre outras situações. Mas os interesses de mercado podem aprofundar ainda mais a crise educacional e da formação humana ao expor, por exemplo, a EJA e o ensino médio às medidas de ensino a distância, com o viés da redução curricular e a submissão da educação aos interesses empresariais.

José Marcelino de Rezende Pinto - Já disse antes, essa decisão lamentável para a história da educação pública do País decorreu diretamente da ação de Binho Marques e Maria Helena de Castro. Curiosamente, ambos, em seus respectivos momentos de poder, ela no Inep; ele na Sase, foram os responsáveis pela implantação do CAQ, ela no Fundef; ele, no Fundeb, e fracassaram. Em particular, o ex-Secretário de Articulação com os Sistemas de Ensino produziu o lamentável “Documento" (CAQi: Custo Aluno Qualidade Inicial para Contratação de Consultoria na Modalidade Produto - CNE/UNESCO - 914BRZ1050.3 TOR 04/2017) que serviu de base ao parecer de Maria Helena de Castro, tão funcional aos interesses do Governo Temer, o mesmo que derrubou a presidente Dilma, conforme didaticamente explicado em entrevista pelo presidente da Câmara, Rodrigo Maia. E o mais melancólico de todo esse episódio: a Câmara de Educação Básica 
(CEB) do CNE, com composição alterada pelo governo golpista, entendeu-se incompetente, desrespeitando a decisão anterior da própria CEB. Eu diria que todo o processo que resultou na revogação do Parecer 8/2010 foi um caso de incompetência generalizada. Mas não sejamos ingênuos, essa decisão foi fundamental aos interesses do Executivo que estava sendo acossado por decisões judiciais que exigiam o cumprimento do Parecer 8/2010 e a implantação imediata do CAQi, tendo em vista o prazo dado pelo PNE em sua meta 20. Saudades de Anísio Teixeira. Resta uma pergunta: por que, nos governos populares, o Executivo não foi capaz de enviar um projeto de lei criando um CNE de Estado e não de governo? Saudades do substitutivo de LDB do então deputado Jorge Hage que tratava do assunto.

Carlos Augusto Abicalil - O marco do golpe jurídico/parlamentar contra a presidenta Dilma, em 2016, espraiou-se em muitas instâncias. Entre elas, o próprio CNE. Basta verificar os processos de indicação e nomeação posteriores. O discurso contundente de ajuste fiscal, de redução das capacidades do Estado, da relativização dos direitos sociais, da imposição do teto dos gastos e do avanço de posições ultraliberais e privatistas predomina e forma maiorias. Embora presente, também, nas etapas anteriores, atua, agora, sem restrições, ressignificando termos e alterando posições, fundado numa maioria interna ocasional e restritiva da participação social. As presenças e as ausências na ocasião da nova deliberação "revisora" oferecem evidências que se expressam também na dinâmica parlamentar de formulação do Fundeb (com ampliação reduzida, pautado em resultados educacionais e aberto ao financiamento da oferta privada, sob o argumento da liberdade de escolha das famílias) e na regulamentação dos artigos 23 e 214 da Constituição Federal.

\section{É possível explicitar as mudanças provocadas na educação básica, em especial, com relação ao valor do gasto por aluno, pela existência do Fundeb? Como esse valor se relaciona ao CAQi?}

Gilmar Soares Ferreira - O próprio parecer 8/2010 traz em seu bojo avaliações do que significou a adoção do Fundef e posteriormente do Fundeb, como subvinculação dos recursos da educação para assegurar a manutenção e valorização do magistério e dos profissionais da educação, bem como percentuais mínimos para pagamento de salários, mesmo que isso esteja, no momento, assegurado apenas aos professores. Em que pese as ações desenvolvidas por alguns estados e municípios (seus governos, ao desviar da sociedade a atenção para os recursos constitucionais da educação [25\% mínimos]) e centradas apenas no Fundef e Fundeb, as experiências da criação de melhores condições de piso, carreira, jornada e formação profissional possibilitaram um salto de qualidade na vida profissional dos educadores. Também a manutenção e desenvolvimento do ensino, em infraestrutura e aquisição de materiais pedagógicos, possibilitaram revoluções nos resultados de aprendizagem, principalmente onde a participação social “...por que, nos governos populares, o Executivo não foi capaz de enviar um projeto de lei criando um CNE de Estado e não de governo?" (José Marcelino Rezende Pinto) 
efetivou o acompanhamento dos investimentos. Ao definir um valor mínimo por aluno, ao estabelecer o acompanhamento social desse investimento, os recursos ganharam a condição de favorecer quem realmente precisa do recurso: o estudante. O CAQi, como referência de qualidade para o início da experiência educacional de cada estudante, tendo como referência o Fundeb, possibilitará maiores e melhores condições de acesso e permanência dos estudantes nas escolas públicas. Aliada ao aprimoramento das práticas de gestão, sem se deixar levar pelos "encantos" da privatização e terceirização, a adoção do CAQi proporcionará um salto de qualidade na formação humana, cidadã e profissional do educando. Como pai de estudantes na escola pública, meu desejo é que meus filhos sejam desafiados para a pesquisa e construção do pensamento coletivo, eles que vivem em plena era do youtube e seus vídeos, que muitas vezes não oferecem muito sentido para a sua formação, mas que são desejados pela condição de imagem ou da tecnologia que atrai. A escola continuará como espaço de encontro e convivência com o conhecimento. Mas, para isso, é preciso garantir as condições materiais e de pessoal para responder aos desafios do presente. Não podemos sucumbir ao mercado, que apenas quer vender mercadorias sem preocupação com a formação do ser. A luta pelo Fundeb permanente, o CAQi e o CAQ são condição sem a qual a formação desejada e para todos/as não irá acontecer.

José Marcelino de Rezende Pinto - O Fundeb, em especial com o aumento da complementação federal, teve papel fundamental no avanço da equalização do gasto por aluno. A título de exemplo, com a complementação, o valor disponível por aluno no Maranhão é duplicado. No Pará, a ampliação é de quase $80 \%$. Nos outros sete estados que receberam complementação em 2016 (BA, CE, AM, PE, AL, PE, PB), esse acréscimo está abaixo de 40\%, ou seja, o efeito é bem mais tímido. Além disso, para 2019, o valor previsto para os anos iniciais (escolas urbanas) nos nove estados que recebem complementação da União é de $\mathrm{R} \$ 3.238,52$ por aluno-ano, ou seja, R $\$ 270 /$ mês; como garantir

"Não resta dúvida de que, desde o Fundef, a evolução do valor aluno/ ano é positiva na consideração dos valores médios em cada fundo estadual."

(Carlos Augusto

Abicalil) padrão mínimo de qualidade com esse valor? Em nosso entendimento, o valor mínimo do Fundeb deve corresponder ao CAQi. Ora, tomando por base a última simulação da CNDE, com base no Simcaq, tendo como referência o ano de 2017, para os anos iniciais do ensino fundamental, a estimativa obtida para o CAQi foi $76 \%$ acima do valor mínimo do Fundeb. Para as creches em tempo integral, estimou-se um valor 4,5 vezes maior.

Carlos Augusto Abicalil - Não resta dúvida de que, desde o Fundef, a evolução do valor aluno/ano é positiva na consideração dos valores médios em cada fundo estadual. Remanescem, por certo, as necessárias revisões dos fatores de ponderação, notadamente em relação à educação infantil e educação em tempo integral. $\mathrm{O}$ avanço do debate em torno da eficácia da atual metodologia para efeitos de maior equidade e atenção aos entes da federação mais vulneráveis, em função da desigualdade das capacidades tributárias entre municípios de uma mesma UF e de indicadores sociais diversos, parte de pressupostos convergentes no CAQi e tende a formular um modelo de distribuição do futuro 
Fundeb que incorpore a consideração da totalidade dos recursos vinculados (introduzindo o valor aluno-ano total), numa nova modalidade de transferência direta de parcela da complementação da União a esses entes. A apresentação mais nítida desses efeitos se encontra na Nota Técnica 24/2017, da Consultoria Legislativa da Câmara dos Deputados.

\section{O Governo Federal (2019) explicita que tem pronta uma PEC para desvincular recur- sos constitucionais. Que implicações essa ação pode trazer para o financiamento da educação brasileira e, em especial, para o Fundeb e para o CAQ?}

José Marcelino de Rezende Pinto - Cabe inicialmente ressaltar que, com a PEC 95/2016, a vinculação do Art. 212, no que se refere aos recursos federais, já está em vigor. Por outro lado, esse governo e Paulo Guedes, em particular, não estão com essa bola toda. Dito isso, qualquer medida que não implique revogar integralmente a EC 95/2016 só aprofundará a crise sem precedentes por que passam as políticas sociais no País e a economia em geral. Esse Congresso começou a cobrar caro as propostas do Governo, mesmo quando, tendo em vista seu perfil de classe, ele concorda com elas. Além disso, as questões federativas, relativas a interesses de estados e municípios no embate com a União, podem ser uma cunha importante para que os setores comprometidos com a escola pública atuem organizadamente no Legislativo a partir de uma boa articulação e mobilização social. No curto prazo, está difícil de identificar esse movimento, mas a história é boa em pregar peças, à esquerda, mas também, à direita.

Carlos Augusto Abicalil - Representará um retrocesso de décadas na capacidade do estado brasileiro assegurar o direito público subjetivo à educação, agravando os já perversos efeitos da EC 95 - congelamento dos gastos públicos, degradação dos padrões da oferta, precarização das relações e das condições de trabalho, numa trágica e duradoura interação com o empobrecimento da população associada à exclusão social, cultural, com fortes acentos étnicos e regionais, com impactos geracionais gravíssimos. Se uma emenda constitucional dessa natureza for aprovada após a promulgação do futuro Fundeb, o destruirá integralmente. Um eventual CAQi estará destinado à cristalização de privilégios em territórios muito restritos. Afinados, quem sabe, com o pensamento do atual titular do MEC, para quem o "Brasil só tem lugar para os melhores".

Gilmar Soares Ferreira - Em termos de recursos por aluno investido em educação, se cientificamente é comprovado que esses recursos são insuficientes ante a demanda de atendimento digno da população, com a desvinculação voltaremos a conviver com cenários do período do Império e início da República no Brasil, quando o poder central não lograva ser responsável pela educação básica e fundamental, jogando toda a demanda para estados e municípios, o que significa dizer, que se temos exclusão em nossas escolas, a situação será muito pior, pela incapacidade destes entes em garantir e expandir matrículas face à necessidade crescente de atendimento da população. A desvinculação de “...qualquer

medida que não implique revogar integralmente a EC 95/2016 só aprofundará a crise sem precedentes por que passam as políticas sociais no País e a economia em geral." (José Marcelino Rezende Pinto) 
"A desvinculação de recursos para a educação na CF acarretará o fim de diversas políticas que fundamentam ou dão suportes à atividade educacional." (Gilmar Soares Ferreira) recursos para a educação na $\mathrm{CF}$ acarretará o fim de diversas políticas que fundamentam ou dão suportes à atividade educacional. A EC 53/2006, que cria o Fundeb, por exemplo, assegura os princípios constitucionais regulamentados para garantir piso salarial nacional profissional, carreira, jornada, transporte escolar, formação profissional de professores e pessoal técnico e de apoio, contratação de pessoal via concurso ou em excepcionalidade como contratados temporariamente, percentual específico para pagamento de piso salarial aos professores e funcionários. Como o Fundeb é subvinculação da vinculação constitucional de $25 \%$ de receitas oriundas de impostos e transferências constitucionais a serem aplicadas na educação, o fim da vinculação significará um desarranjo constitucional, que implicará na retirada da obrigação do atendimento à demanda da educação. Isso vai significar mais exclusão, mais retrocessos. É preciso dizer que ações desse porte abrem um precedente de desmonte constitucional das instituições que foram criadas e estão voltadas para cobrar o cumprimento dos preceitos constitucionais. Será a desautorização do Ministério Público, dos conselhos, dos próprios tribunais de conta, uma tragédia para o País. De outra parte, a não existência de critérios regulamentadores de aplicação poderá abrir um precedente de farra com os recursos públicos na educação, uma vez que a fiscalização e o controle ficarão impossibilitado pelos aparelhos de Estado e pela população. No caso da CAQ, será uma ausência total de referência para a construção, em curso, do conceito do que seria, de fato, o custo aluno para a qualidade na aprendizagem articulado à valorização profissional. Caso isso aconteça, voltaremos aos tempos coloniais/imperiais da desregulamentação. Ou seja, a população abandonada à própria sorte, abandonada à condenação das elites do atraso, como bem define Jessé de Souza.

\section{Duas outras ideias no âmbito do Poder Federal são a introdução de vales/cheques e o fim da gratuidade na educação ofertada pelo setor público. Os que são contrários a essas ideias de que argumentos precisam para se contrapor a elas?}

Carlos Abicalil - Para os defensores do ajuste fiscal ultraliberal vale a pena lembrar, pelo menos, duas situações presentes: a) já há vale/educação embutido na dedução do Imposto de Renda da Pessoa Física que paga instituição educacional privada, na Pessoa Jurídica que apoia a educação de empregados, nas isenções de mantenedoras declaradas sem finalidade lucrativa ou comunitária, na imunidade tributária de instituições declaradas beneficentes e de assistência social; $b$ ) se o ajuste fiscal deve atuar sobre corte de despesas públicas, não se justifica desviar fundo público para instituições privadas. Para sustentar questões de princípios, vale ressaltar que se trata de direito humano, direito público subjetivo, universal, sem discriminação de qualquer natureza - de status social ou econômico, de localização, renda ou conformação familiar, de tradição cultural ou religiosa. As nações menos desiguais do planeta e consideradas como referenciais em educação asseguram o protagonismo (em alguns casos, exclusividade) da oferta pública 
e a garantia da gratuidade como asseguradora da universalidade do acesso, indicador de equidade e prática de solidariedade social. $\mathrm{O}$ argumento de liberdade de escolha das famílias não pode servir para justificar a destituição de direitos nem a seleção de castas ou a salvação de instituições privadas falimentares em favor de seus donatários. Aqui vale registrar o imperativo de delimitar claramente a barreira entre a promoção do CAQ e a validação do padrão de transferência de fundo público ao interesse privado.

Gilmar Soares Ferreira - Primeiro, argumentar que a escola pública e gratuita é a condição que universaliza a todos/as o acesso à aprendizagem, ao ensino e ao conhecimento. Assim, cabe ao Estado, ante a enorme defasagem em termos de direito à educação no Brasil, assegurar este direito. Em segundo lugar, fazer a memória de que nosso histórico de concentração de renda e de apropriação das estruturas de Estado pelas elites sempre condenaram a maioria da população ao ostracismo educacional, econômico, social e cultural. Nesse caso, a escola é o único espaço plural onde todos podem refletir e aprender a convivência de respeito e harmonia social. Terceiro, é preciso esclarecer a população sobre "o canto da sereia" dos vales-cheques na educação cujo objetivo é submeter os recursos públicos à educação privada. Repassar recursos públicos através de vales-cheques para a população matricular seus filhos em escolas privadas é o mesmo que pagar por um direito que, na prática, os cidadãos já o fazem por meio dos impostos. Como os vales-cheques não serão para todos, assim como as escolas privadas não são para todos, o vaucher promoverá mais segregação econômica e social de setores significativos da população. Afinal, já está comprovado que somente uma educação pública, gratuita, regida pela liberdade de pesquisa, ensino e aprendizagem baseada no diálogo e na democracia, ou seja, na liberdade de manifestar o pensamento, possibilitará a vivência numa sociedade de real vivência democrática. Eis o maior e melhor resultado que uma política de financiamento da educação pode oferecer.

José Marcelino de Rezende Pinto - Os interesses privatistas em educação, que, em cenário de crise, buscam carrear recursos públicos para seus negócios de ensino nunca estiveram tão mobilizados. O FIES foi uma verdadeira dádiva para o capital especulativo na educação superior. Em 2016, contando dinheiro vivo e subsídios implícitos foram mais de R $\$ 30$ bilhões para o FIES; é mais recursos do que tudo o governo federal gastou com manutenção e desenvolvimento do ensino superior no mesmo ano! O foco dos privatistas agora é a educação básica. Falta achar o tal "modelo de negócio". A "turma do Insper", com quase monopólio na mídia, está defendendo que, no Fundeb, os convênios se ampliem para toda a educação básica. Hoje, eles estão previstos para as creches (metade das vagas privadas hoje correspondem a convênios), educação especial e pré-escola, etapas em que os convênios deveriam estar extintos pela regulamentação do Fundeb, mas a legislação posterior foi prorrogando a sua vigência. E por que convênios e "vale-escola" não são o melhor caminho? No caso do Brasil, já existem os convênios na educação infantil com as instituições não lucrativas, os programas de compra de vagas 
em particulares (o que é contra a lei) e o modelo de Organizações Sociais, onde o poder público constrói o prédio e transfere a gestão. Em todas essas experiências a opção do poder público tem como foco reduzir os custos. O resultado é uma qualidade muito inferior ao atendimento direto, clientelismo político na oferta de vagas, pois muitas dessas instituições estão sob controle de vereadores, além da ausência de qualquer mecanismo de gestão democrática e controle social. São instituições que pagam baixos salários, não respeitam a hora atividade, pois a lei do PSPN não se aplica ao setor privado e as condições de oferta são extremamente precárias. A experiência internacional, seja no Chile, grande cobaia dos experimentos neoliberais nos tempos de Pinochet, seja nos EUA, com escolas "charters" ou com os "vouchers" mostra que o sistema tende a segmentar a oferta, tornando o sistema mais heterogêneo, o que dificulta ainda mais a melhoria da qualidade do ensino como um todo. Em educação, quanto mais juntos e misturados os diferentes grupos sociais em um mesmo sistema educacional, melhor, ao contrário do senso comum. Imagine o grau de escolha de uma família que mora na periferia com um "vale educação" mensal de R \$ 270,00? Com certeza o mercado ofereceria um "produto" por esse valor, mas no padrão "loja de 1,99". Países que deram certo, como Finlândia e Coréia, apresentam um sistema nacional de educação, em que o Estado controla fortemente a formação de professores, que são valorizados e escolhidos entre os alunos mais preparados do ensino médio. Por isso gastam por aluno um valor de três a quatro vezes superior ao praticado no Brasil. É mais eficiente e mais barato montar um sistema público de qualidade. Em educação não existem atalhos.

O corte de verbas para a educação básica e superior articulado às políticas de ajustes fiscais em curso secundariza as diretrizes, metas e estratégias do Plano Nacional de Educação. Quais os impactos disso tudo para a organização, gestão e financiamento da educação no País?

José Marcelino de Rezende Pinto - O Brasil vive seu 'bônus populacional', um momento em que temos uma parcela significativa da população em condições de formação e ingresso no mercado de trabalho. É hora de investir pesadamente em sua formação e, se há uma evidente crise internacional, com elevadas taxas de desemprego, um motivo a mais para garantir educação continuada para os jovens egressos do ensino médio e superior (uma minoria ainda no Brasil) e, principalmente, para assegurar um ensino de qualidade para as crianças e jovens que estão, ou deveriam estar, na educação básica ou superior. Negar essa formação é negar seu futuro e, por consequência, nossa viabilidade enquanto nação soberana e consciente de suas potencialidades. Nossa elite envia seus filhos para o exterior, fecha nossas indústrias e quer viver de exportação de bens primários, ou da 'bolsa família rica' paga pelo Governo Federal aos milionários que vivem de juros e encargos da dívida pública (R\$ 800 bilhões no orçamento de 2020). Para 
reverter essa situação, só a união das oposições conscientes, sem personalismos, o retorno humilde às ruas, conversando com os milhões de brasileiros pobres que foram enganados pelo canto de sereia da direita (não é a primeira vez na história), recuperando nossa capacidade de mobilização e transformação, como foi feito na época da ditadura. E isso demanda paciência, visão estratégica, união das forças progressistas e o PNE como norte. Mesmo com suas contradições, trata-se de uma lei aprovada pelo Congresso Nacional que deve ser cumprida.

Carlos Augusto Abicalil - Há um território de barbárie legitimada pelo Estado vocacionado exclusivamente ao interesse do mercado, deliberadamente avesso à proteção social e à mediação de conflitos. $\mathrm{O}$ abandono do $\mathrm{PNE}$, a desconsideração de instâncias de consulta, formulação, pactuação, acompanhamento e controle social, o desprezo pela consistência do argumento e a aversão ao debate público revelador do contraditório não significam ausência de um programa de governo. Ao contrário, evidenciam um ideário de nação pré-moderna, embora nutrida pela sofisticação da guerra híbrida. Por outro lado, o caldo de pluralidade política, a inércia própria de instituições e organizações atuam como resistência considerável, embora insuficiente. As contradições discursivas e as exigências materiais do processo produtivo e gerador da riqueza real já demostram insatisfações visíveis e crescente descrédito nas estratégias de "saída" para a crise econômica, para a criminalização da política e a partidarização do corpo judicial. Igualmente, percebe-se a corrosão da imagem pública interna e externa do Estado nacional e de seus negócios próprios. Em plena expansão da indústria 4.0 e alvorecer de sistemas produtivos 5.0 (inclusive de novos processos relativos aos produtos primários controlados artificialmente e novos materiais), o Estado pré-moderno perde funcionalidade. Não se sustentará sem reversão. Que seja breve. Para isso nos movemos. A história não acabou.

Gilmar Soares Ferreira - No projeto de ultradireita que vem sendo implantado no País, mais do que secundarizar, o corte de verbas e o ajuste fiscal anulam todo o PNE. Agora, não é somente a ausência de recursos que impera, a exemplo do PNE vigente entre 2001 e 2010, em que FHC vetou o 7\% do PIB. Agora, temos outra concepção de educação a ser implementada, pautada por princípios da naturalização da segregação social, da apartação econômica, política e social, a exemplo do projeto Escola Sem Partido e do homeschooling. Outra concepção é a mercantilização total, o liberalismo aplicado de forma extrema. Os impactos já estão sendo danosos, uma vez que o conhecimento não é visto como uma construção, é imposição numa relação bancária e conteudista. Não há diálogo na relação ensino-aprendizagem. A linha comportamental estimulo-resposta, o ensino decoreba, o conteúdo pasteurizado, comprimido, apostilado, condicionado passa a ser a matriz curricular. Voltaremos, assim, ao ensino bancário, baseado nas provas para aferir aprendizagem, descolado da vivência e seus significados e na exclusão tácita pela reprovação ou promoção automática. Nesta linha, a marca da gestão é a economicista, tecnicista, de resultados. Não faltará dinheiro público para as empresas e “...o Estado prémoderno perde funcionalidade. Não se sustentará sem reversão. Que seja breve. Para isso nos movemos. A história não acabou." (Carlos Augusto Abicalil ) 
para as contratações, desvinculadas da via efetiva através de concurso, onde servidores "treinados" aplicarão, de forma silenciosa e sem crítica, o conteúdo, desvinculado da via educadora dessas relações. Enfim, se os segmentos escolares, a partir do chão da escola, não se rebelarem, estaremos fadados a transformar nossas escolas nas gélidas construções e instituições educacionais, onde o que menos importa é a relação humana, afetiva, que nos torna. a todos, aprendizes. Interessa ao mercado que a escola e a universidade sejam, de forma direta, espaços do lucro sem complicações. Se nossas escolas sucumbirem às relações empresariais, às parcerias público-privadas, aí, sim, elas serão muito mais excludentes do que se apresentam atualmente. 